\title{
Variability in Mechanical Ventilation: What's All the Noise About?
}

\author{
Bhiken I Naik MB BCh, Carl Lynch III MD PhD, and Charles G Durbin Jr MD FAARC
}

\author{
Introduction \\ Physiological Respiratory Variability \\ Central and Peripheral Respiratory Control \\ Biological Systems and Noise \\ Stochastic Resonance \\ Limitations of Stochastic Resonance \\ Intermittent Deep Inflation: Sigh Breath \\ ARDS and Variability in Mechanical Ventilation \\ Controlled Variable Ventilation and ARDS \\ Patient-triggered Variable Ventilation and ARDS \\ Sigh Breaths and ARDS \\ Variable Ventilation in Non-ARDS Models \\ Practical Applications for Variable Ventilation \\ Conclusions
}

\begin{abstract}
Controlled mechanical ventilation is characterized by a fixed breathing frequency and tidal volume. Physiological and mathematical models have demonstrated the beneficial effects of varying tidal volume and/or inspiratory pressure during positive-pressure ventilation. The addition of noise (random changes) to a monotonous nonlinear biological system, such as the lung, induces stochastic resonance that contributes to the recruitment of collapsed alveoli and atelectatic lung segments. In this article, we review the mechanism of physiological pulmonary variability, the principles of noise and stochastic resonance, and the emerging understanding that there are beneficial effects of variability during mechanical ventilation. Key words: variability; noise; stochastic resonance; ARDS; recruitment. [Respir Care 2015;60(8):1203-1210. (c) 2015 Daedalus Enterprises]
\end{abstract}

\section{Introduction}

Controlled mechanical ventilation is often used for the management of patients with respiratory failure and transiently during the intraoperative period. Mechanical ven-

\footnotetext{
The authors are affiliated with the Department of Anesthesiology, University of Virginia, Charlottesville, Virginia.

This study was supported by departmental funding. The authors have

Correspondence: Bhiken I Naik MB BCh, University of Virginia, PO Box 800710, Charlottesville, VA 22908. E-mail: bin4n@virginia.edu.
}

DOI: $10.4187 /$ respcare.03794 tilation employed during these periods is characterized by a fixed breathing frequency and monotonous tidal volume $\left(\mathrm{V}_{\mathrm{T}}\right)$ created by a change in airway pressure with either volume or pressure control mode. This is in sharp contrast to spontaneous breathing, which demonstrates small breathto-breath variations in both $\mathrm{V}_{\mathrm{T}}$ and breathing frequency with interspersed, intermittent, deep-inflation breaths (sighs or augmented breaths). In 1964, Bendixen et al $^{1}$ noted the significant short-term and long-term variability in ventilatory patterns in healthy adults.

Although it remains the mainstay of therapy for ARDS and other forms of lung injury, there is mounting evidence of surrogate injury associated with mechanical ventilation. ${ }^{2,3}$ Traditionally, ventilator-induced lung injury is mitigated by reducing $\mathrm{V}_{\mathrm{T}}$ and by the appropriate use of PEEP.,2,3 


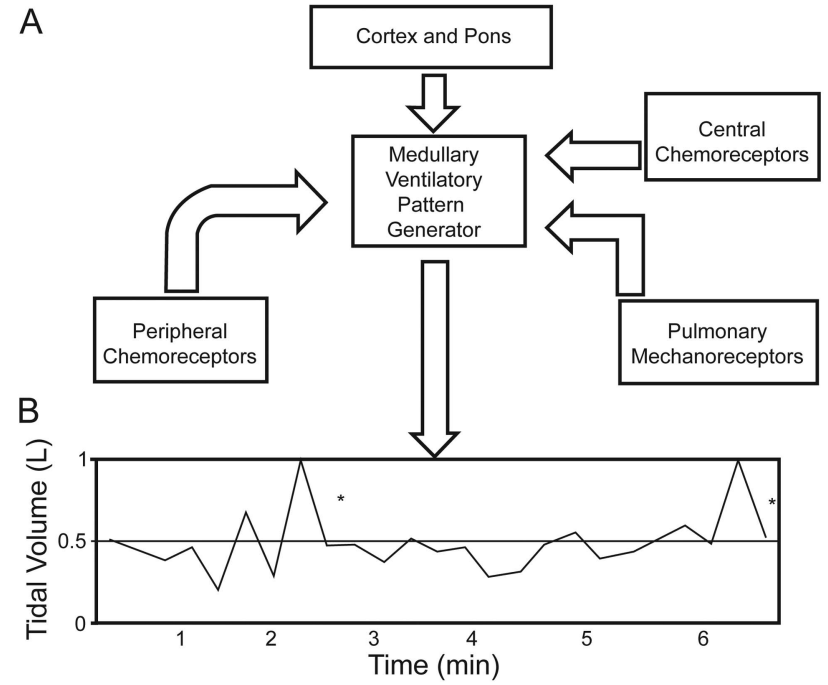

Fig. 1. A: Ventilatory pattern determined by input from the cortex, pons, pulmonary mechanoreceptors, and central and peripheral chemoreceptors. B: Breath-to-breath variation in tidal volume over time. ${ }^{*}$ Intermittent deep-inflation breaths or sighs.

However there is increasing preclinical evidence that mimicking the physiological variability during controlled and patient-triggered mechanical ventilation is a novel method to facilitate lung recruitment and reduce the risk of ventilator-induced lung injury. ${ }^{4-7}$ In this review article, we discuss normal physiological respiratory variability and the salutary effects on alveolar recruitment, ventilation/perfusion matching, and systemic oxygenation that occur when variability is applied to a variety of lung injury models.

\section{Physiological Respiratory Variability}

The characteristic pattern of spontaneous breathing is the result of integration of input from the higher central nervous system, brainstem control centers, chemoreception, and pulmonary mechanoreceptors (Fig. 1). ${ }^{8}$ The breathing pattern is adapted to meet the immediate metabolic demands while reducing the work of breathing by optimizing ventilation and perfusion.

The pattern of spontaneous breathing represents a complex interaction of structured time-dependent breath-tobreath changes coupled with random variations. These fluctuations are due to an inherent homeostatic mechanism and feedback loops that buffer changes to the respiratory system and attempt to return them to their dynamic steady state. This results in a highly variable, unpredictable breathing pattern.

\section{Central and Peripheral Respiratory Control}

The 4 major sites for respiratory control are the central respiratory control center, pulmonary mechanoreceptors, and central and peripheral chemoreceptors located in the brain and aorta, respectively. The central respiratory control center is located in the medulla and is functionally responsible for setting the rhythmic respiratory pattern through the ventilatory pattern generator. Modulation of the rate and amplitude of the respiratory pattern is accomplished via the integrator. ${ }^{8}$ The integrator receives multiple inputs from higher centers, including the hypothalamus, amygdala, cerebral cortex, and limbic system, and from the central and peripheral chemoreceptors (see Fig. 1). The central chemoreceptors are a group of specialized cells found on the ventrolateral surface of the medulla and respond to changes in the $\mathrm{pH}$ of the cerebrospinal fluid. ${ }^{8}$

In contrast, the peripheral aortic and carotid chemoreceptors respond to changes in $\mathrm{P}_{\mathrm{O}_{2}}, \mathrm{P}_{\mathrm{CO}_{2}}$, and $\mathrm{pH}$. The final respiratory control mechanism is through the pulmonary mechanoreceptors. These include the rapidly adapting pulmonary stretch receptors, slowly adapting pulmonary stretch receptors, and juxta-alveolar receptors. The rapidly adapting pulmonary stretch receptors are located in the tracheobronchial superficial mucosal layer and result in an increase in airway resistance, reflex apnea, and coughing. ${ }^{8}$ The slowly adapting pulmonary stretch receptors are found in the tracheobronchial smooth muscle layer, are activated by lung inflation via the vagal afferent myelinated fibers, and result in termination of the inspiratory process. The juxta-alveolar receptors lie close to the pulmonary microcirculation and respond to mechanical and chemical irritation in the pulmonary interstitium. They are responsible for the subjective sensation of dyspnea and the respiratory pattern characterized by rapid shallow breathing.

\section{Biological Systems and Noise}

\section{Stochastic Resonance}

Many biological systems are characterized by a continuously variable response to changing intrinsic or extrinsic input (eg, sinus arrhythmia occurs in responses to changes in ventilation). Analysis of these biological responses demonstrates irregular random fluctuations of the output signal, characteristic of noise. ${ }^{9}$

In biological systems, noise traditionally refers to variable output with similar experimental designs or the inability to distinguish biological signals from background fluctuation. ${ }^{10}$ These are undesirable side effects of noise. However, when good noise (where both frequency and amplitude can be controlled) is added to a previously monotonous biological system, signal output can be improved. This paradoxical effect of noise is termed stochastic resonance.

Stochastic resonance was first described by Roberto Benzi while studying noise-enhancing signal processing. ${ }^{10}$ The primary feature of a nonlinear system with stochastic 


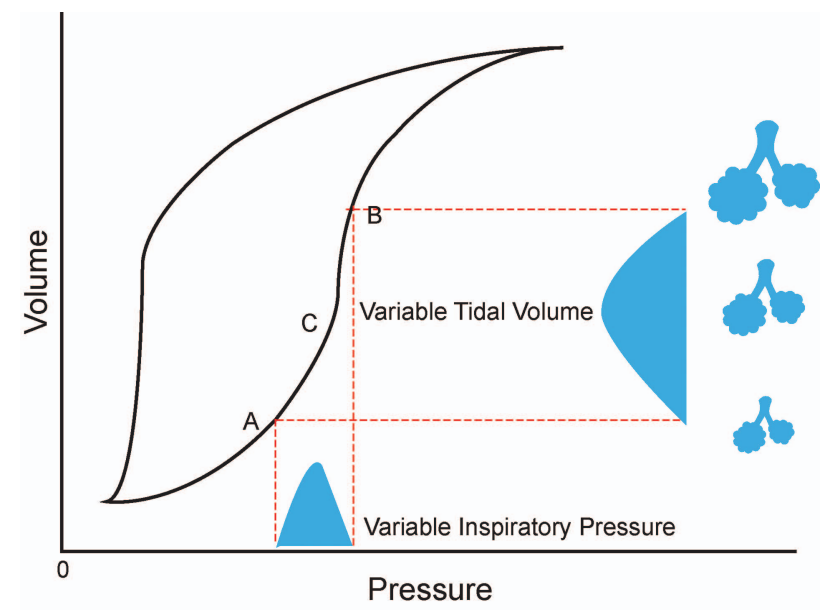

Fig. 2. Pressure-volume curve with either variable tidal volume $\left(V_{T}\right)$ or variable inspiratory pressure normally distributed around point $\mathrm{C}$, which represents an ideal low $\mathrm{V}_{\mathrm{T}}$. Progressive recruitment of alveoli by stochastic resonance is shown. Point $A=$ lower inflection point; point $\mathrm{B}=$ upper inflection point.

resonance is an increased quality or metric of the output signal with the addition of noise. ${ }^{11}$ The improved output quality is greatest at a single maximum non-zero point termed the stochastic resonance peak, equivalent to the resonance frequency of a mechanical system. The phenomenon of stochastic resonance has been quantified and reported in varied biological and nonbiological systems, such as climate and financial models. ${ }^{10}$

The static pressure-volume curve of the lung has classic nonlinear features with a steep pressure-volume relationship above the lower inflection point, which flattens above the upper inflection point (Fig. 2). Stochastic resonance can be observed theoretically by randomly varying the inspiratory pressure or $\mathrm{V}_{\mathrm{T}}$ in a gaussian distribution above the lower inflection point. The theoretical benefits are due to the marked nonlinearity above this critical point. The lung volume gained with the higher inspiratory pressures or $\mathrm{V}_{\mathrm{T}}$ will be significantly greater than the lung volume lost at the lower inspiratory pressures or $\mathrm{V}_{\mathrm{T}} \cdot{ }^{4,5}$ Additional potential benefits of stochastic resonance are suggested by the work of Suki et al, ${ }^{11}$ who demonstrated that once the critical opening pressure of a collapsed alveolus is superseded, adjacent alveoli with lower critical opening pressures will open in a series of avalanches. This is equivalent to the stochastic resonance peak of the pulmonary pressure-volume relationship and can potentially play an important role in the $\mathrm{V}_{\mathrm{T}}$ recruitment of collapsed lung units. The phenomenon of stochastic resonance can be observed by varying either inspiratory pressures or $\mathrm{V}_{\mathrm{T}}$. When varying the $\mathrm{V}_{\mathrm{T}}$, the overall effect is a reduction in mean airway pressure for the same exhaled minute volume. ${ }^{4}$

\section{Limitations of Stochastic Resonance}

Although addition of variability to previously monotonous biological systems can be beneficial, extremes of variability during mechanical ventilation may be detrimental. The one negative study of variable ventilation in a canine model of acute lung injury used a highly variable signal at or above the point on the pressure-volume curve where noise-related benefit can be derived. ${ }^{4}$ The addition of noise at or above the upper inflection point (where the pressure-volume curve flattens out) could have potentially deleterious effects due to increased mechanical strain on some alveoli with minimum gain in the $\mathrm{V}_{\mathrm{T}}{ }^{4}$

Under these circumstances, the risk of alveolar overdistention supersedes the beneficial effect of alveolar recruitment, resulting in volume-related, ventilator-induced lung injury. Therefore, the type of noise signal implemented in conjunction with the underlying pulmonary physiological state can potentially have a significant impact on outcomes.

\section{Intermittent Deep Inflation: Sigh Breath}

An intermittent deep-inflation breath provides an additional normal mechanism of creating respiratory variability. The physiological sigh or deep-inflation breath is characterized by a large $\mathrm{V}_{\mathrm{T}}$ breath $\left(2-3 \times \mathrm{V}_{\mathrm{T}}\right)$ occurring at varying frequency (1-25 breaths/h) during spontaneous breathing. ${ }^{1,12}$ The sigh breath is triggered by the rapidly adapting pulmonary stretch receptors employing an inspiration-augmenting reflex from the vagal afferents. ${ }^{13-15}$ Central pacemaker control for the augmented breath appears to be integrated but autonomous to the control mechanism for eupnea. ${ }^{16}$ The augmented breath serves multiple physiological functions, including reaeration of collapsed alveoli, improved functional residual capacity, and reduction of the pulmonary shunt. ${ }^{1}$ The sigh breath also plays a vital role in resetting the breathing pattern. Vlemincx et al ${ }^{17}$ demonstrated that when breathing becomes either excessively random or lacks significant variability, the sigh breath is able to restore the deterministic nonrandom variability.

The frequency and pattern of sigh respirations can be altered under certain circumstances. Sigh respirations are eliminated following administration of opiates. ${ }^{18,19}$ However, Bell et $\mathrm{al}^{19}$ noted the return of augmented breath when an animal was exposed to a hypoxic mixture. Volatile and total intravenous anesthesia is not associated with any significant change in the frequency of sigh breaths. ${ }^{20,21}$ However, propofol anesthesia is associated with a reduction in mean inspiratory flow of the augmented breath and subsequent timing of the succeeding breath. ${ }^{20}$

In summary, $\mathrm{V}_{\mathrm{T}}$ and breathing frequency are constantly changing in the normal breathing pattern and are likely physiologically beneficial to normal lungs. The evidence 
for adding variability during controlled and patients-triggerred mechanical ventilation for ARDS and non-ARDS lung pathology is presented below.

\section{ARDS and Variability in Mechanical Ventilation}

ARDS is caused by either a primary injury to the lung or a remote extrapulmonary injury with associated lung involvement. With primary ARDS, the injury evolves mainly from the alveolar epithelial membrane with a cascade of changes, including increased alveolar edema, loss of surfactant, and subsequent healing with fibrosis. ${ }^{22}$ In contrast, extrapulmonary ARDS begins predominately with the pulmonary endothelium with increased vascular permeability. Both forms of ARDS are characterized by increased pulmonary edema and alveolar collapse that is heterogeneously distributed throughout the lung, with the dependent segments most affected. ${ }^{22}$ This results in worsening of the ventilation/perfusion mismatch characterized by increasing shunt and the development of progressive hypoxemia. Work of breathing increases dramatically, and respiratory exhaustion may result in acute mechanical respiratory failure.

Controlled mechanical ventilation remains the cornerstone of management of patients with ARDS. However, a careful ventilator management strategy is required to prevent ventilator-induced lung injury. Ventilator-induced lung injury may occur with inappropriately high alveolar distending pressure or volume, with inappropriate PEEP, or when a high ventilatory $\mathrm{V}_{\mathrm{T}}$ is delivered $(>8 \mathrm{~mL} / \mathrm{kg}){ }^{3}$

Keeping the $\mathrm{V}_{\mathrm{T}}$ to $\leq 6 \mathrm{~mL} / \mathrm{kg}$ as part of a strategy to prevent ventilator-induced lung injury has been shown to reduce mortality and ICU stay in both subjects with and without ARDS. ${ }^{2,23,24}$ However, applying a low- $\mathrm{V}_{\mathrm{T}}$ strategy without appropriate use of PEEP can result in alveoli collapse. In 15 subjects with ARDS, Richard et al ${ }^{25}$ demonstrated that low $\mathrm{V}_{\mathrm{T}}(6 \mathrm{~mL} / \mathrm{kg})$ with PEEP set at the lower inflection point was associated with significant alveolar derecruitment, which improved with application of a recruitment maneuver. More importantly, Levin et $\mathrm{al}^{26}$ demonstrated an increased risk of 30-d mortality with low intraoperative $\mathrm{V}_{\mathrm{T}}$ and minimum PEEP in subjects without ARDS.

\section{Controlled Variable Ventilation and ARDS}

Variable ventilation was first described by Lefevre et al ${ }^{6}$ in a porcine model of oleic acid-induced acute lung injury. Oleic acid was infused in 17 animals until the systemic $\mathrm{P}_{\mathrm{aO}_{2}}$ was $<125 \mathrm{~mm} \mathrm{Hg}$ with an $\mathrm{F}_{\mathrm{IO}_{2}}$ of 0.5. Animals were then randomly assigned to receive either conventional ventilation at a rate of 20 breaths/min or variable ventilation. The baseline pre-oleic acid-induced injury $\mathrm{V}_{\mathrm{T}}$ in the conventional ventilation group was $427 \pm 64 \mathrm{~mL}$ versus $424 \pm 46 \mathrm{~mL}$ in the variable ventilation group. The variable ventilation group had a breathing frequency of $20 \pm 2.3$ breaths/min (range of $15-27$ breaths/min), with 369 different breathing frequencies and reciprocal changes in the $\mathrm{V}_{\mathrm{T}}$ over a 1,089 -s period. The $\mathrm{V}_{\mathrm{T}}$ varied from 75 to $135 \%$ of the mean $\mathrm{V}_{\mathrm{T}}$ in this computer-controlled model of variable ventilation. After $4 \mathrm{~h}$ of mechanical ventilation, the variable ventilation group demonstrated a significant improvement in arterial oxygenation $(140 \pm 44 \mathrm{~mm} \mathrm{Hg}$ vs $75 \pm 20 \mathrm{~mm} \mathrm{Hg}, P<.05)$ with a concomitant lower shunt fraction $\left(\dot{\mathrm{Q}}_{\mathrm{S}} / \dot{\mathrm{Q}}_{\mathrm{T}}, 8.5 \pm 3 \%\right.$ vs $\left.13.1 \pm 3 \%, P<.05\right)$. The variable ventilation group also demonstrated a statistically significant higher respiratory compliance $(0.62 \pm 0.18$ $\mathrm{mL} / \mathrm{cm} \mathrm{H}_{2} \mathrm{O} / \mathrm{kg}$ vs $\left.0.49 \pm 0.16 \mathrm{~mL} / \mathrm{cm} \mathrm{H}_{2} \mathrm{O} / \mathrm{kg}, P<.05\right)$ with lower postmortem wet/dry lung weight $(8.1 \pm 0.9 \mathrm{vs}$ $9.3 \pm 0.6, P=.01)$. This beneficial effect of reduced $\dot{\mathrm{Q}}_{\mathrm{S}} / \dot{\mathrm{Q}}_{\mathrm{T}}$ and improved oxygenation with variable ventilation has been demonstrated with and without the use of PEEP. 6,7

The improvement in respiratory compliance and systemic oxygenation and the reduced $\dot{\mathrm{Q}}_{\mathrm{S}} / \dot{\mathrm{Q}}_{\mathrm{T}}$ are related to several salutary effects of variable ventilation on pulmonary alveolar mechanics. Arold et a ${ }^{27}$ demonstrated a nearly 2-fold increase in bronchoalveolar lavage phospholipid surfactant levels $(160 \pm 28 \mathrm{mg} / \mathrm{kg}$ vs $84 \pm 29 \mathrm{mg} / \mathrm{kg}, P<$ $.05)$ with reduced alveolar protein content $(17.2 \pm 3.9$ $\mathrm{mg} / \mathrm{kg}$ vs $12.0 \pm 1.6 \mathrm{mg} / \mathrm{kg}, P<.05)$ with variable ventilation compared with conventional mechanical ventilation. Furthermore, variable ventilation also facilitates more uniform lung recruitment during acute lung injury. Using computed tomography in a porcine oleic acid-induced lung injury model, Graham et al28,29 demonstrated significantly improved recruitment of nonaerated and poorly aerated lung areas without a concomitant increase in hyperaerated lung areas. In addition, there is evidence that the recruitment associated with variable ventilation is more sustained than that with monotonous controlled mechanical ventilation when used in conjunction with PEEP. ${ }^{30}$ In an excised saline lavage bovine lung injury model, Bellardine et $\mathrm{al}^{30}$ demonstrated longer recruitment times with a combination of high $\mathrm{V}_{\mathrm{T}}$ and variable ventilation compared with high $\mathrm{V}_{\mathrm{T}}$ and conventional ventilation. These findings suggest that variable ventilation is able to provide continuous physiological recruitment without the associated risk of ventilator-induced lung injury.

There are limited studies of variable ventilation in human subjects. Boker et al ${ }^{31}$ conducted a prospective study with 40 subjects undergoing elective open abdominal aortic aneurysmectomy procedures. This procedure is associated with significant intraoperative atelectasis. Twenty subjects each were randomized to either conventional ventilation $\left(\mathrm{V}_{\mathrm{T}}\right.$ of $10 \mathrm{~mL} / \mathrm{kg}$, breathing frequency of 10 breaths/min, zero PEEP) or variable ventilation (mean $\mathrm{V}_{\mathrm{T}}$ of $10 \mathrm{~mL} / \mathrm{kg}$, minimum $\mathrm{V}_{\mathrm{T}}$ of $6.4 \mathrm{~mL} / \mathrm{kg}$, maximum $\mathrm{V}_{\mathrm{T}}$ of $14.6 \mathrm{~mL} / \mathrm{kg}$ ). The variable ventilation group dem- 
onstrated higher arterial oxygenation and pulmonary compliance with lower $\mathrm{P}_{\mathrm{aCO}}$ and dead-space ventilation. The major limitation of this study was the absence of PEEP in the conventional ventilation group. In contrast, Kowalski et al ${ }^{32}$ performed a crossover trial in 8 subjects with ARDS undergoing protective lung ventilation. They reported a better oxygenation index $\left(\mathrm{F}_{\mathrm{IO}_{2}} \times\right.$ mean airway pressure $\times$ [100/ $/ \mathrm{P}_{\mathrm{aO}_{2}}$ ], variable ventilation: $7.1 \mathrm{~cm} \mathrm{H}_{2} \mathrm{O} / \mathrm{mm} \mathrm{Hg}$ vs conventional ventilation: $11.5 \mathrm{~cm} \mathrm{H}_{2} \mathrm{O} / \mathrm{mm} \mathrm{Hg}, P=.034$ ) and higher lung compliance (variable ventilation: 0.36 $\mathrm{mL} / \mathrm{cm} \mathrm{H} \mathrm{H}_{2} \mathrm{O} / \mathrm{kg}$ vs conventional ventilation: 0.34 $\mathrm{mL} / \mathrm{cm} \mathrm{H}_{2} \mathrm{O} / \mathrm{kg}, P=.049$ ) when variable ventilation was instituted. Although the number of human studies on variable ventilation is limited, the aforementioned studies are congruent with the positive findings previously reported in animal models.

\section{Patient-triggered Variable Ventilation and ARDS}

The beneficial effects of noise are also seen with spontaneous ventilation modes. Conventional pressure support ventilation (PSV) is a spontaneous mode of ventilation that is either flow- or pressure-triggered, pressure-limited, and either flow- or time-cycled. Because PSV is pressurelimited, the $\mathrm{V}_{\mathrm{T}}$ can remain relatively constant if respiratory compliance does not change rapidly ( $\min$ to $\mathrm{h}$ ). Varying the inspiratory pressure randomly in a normal distribution will result in stochastic resonance as described previously. Noisy PSV was first described by Gama de Abreu et $\mathrm{al}^{33}$ in a porcine surfactant depletion model. They reported that noisy PSV decreased venous admixture compared with PSV alone (11.1\% [5.5-20.3] versus $16.5 \%$ [7.9-29.8], $P<.05)$. Using florescent, color-labeled microspheres, they also demonstrated that noisy PSV improved pulmonary blood flow to the nondependent areas of the lung, thus reducing the $\dot{\mathrm{Q}}_{\mathrm{S}} / \dot{\mathrm{Q}}_{\mathrm{T}}$. With noisy PSV, the amount of variability can influence both recruitment and patient-ventilator synchrony and comfort. Normally distributed inspiratory pressures with mean \pm SD of $1 \pm$ $0.075,1 \pm 0.15,1 \pm 0.30$, and $1 \pm 0.45$ of the baseline mean pressure support required to maintain a $V_{T}$ of 6 $\mathrm{mL} / \mathrm{kg}$ were studied by Spieth et $\mathrm{al}^{34}$ in a porcine surfactant depletion model. They found that a variability of $30 \%$ (mean $\pm \mathrm{SD}$ of $1 \pm 0.30$ ) was associated with the highest $\mathrm{P}_{\mathrm{aO}_{2}} / \mathrm{F}_{\mathrm{IO}_{2}}$ with the lowest $\dot{\mathrm{Q}}_{\mathrm{S}} / \dot{\mathrm{Q}}_{\mathrm{T}}$.

\section{Sigh Breaths and ARDS}

As noted above, sigh breaths are normal physiological respiratory events that are thought to assist with re-recruitment of atelectatic lung units and to reset the breathing pattern when it becomes either excessively chaotic or monotonous. ${ }^{17}$ The sigh breath can be considered a limited form of noisy respiration. The first description of the sigh breath was reported in 1919 by Haldane et $\mathrm{al}^{35}$ in their study of shallow-breathing patterns in healthy adults. Subsequently, Laver et al ${ }^{36}$ demonstrated an improvement in pulmonary compliance in subjects undergoing general anesthesia when an intermittent deep-inflation breath was applied. In this early study of deep-inflation breaths, PEEP was not utilized, which may explain the marked improvement in pulmonary compliance with an intermittent augmented breath. ${ }^{37}$ Based on these earlier studies, sigh breaths were incorporated into mechanical ventilators. However, with the development and popularization of PEEP, the sigh breath has been relegated to antiquity. ${ }^{38}$

More recent studies of sigh respiration in ARDS have demonstrated consistent improvement in pulmonary parameters of gas exchange during both supine and prone ventilation. ${ }^{39-42}$ In these studies, protective lung strategies (low $\mathrm{V}_{\mathrm{T}}$ and PEEP) were utilized and subjects underwent controlled mechanical ventilation. The benefit of a sigh breath in these studies is likely related to the re-recruitment of atelectatic lung units when a low- $\mathrm{V}_{\mathrm{T}}$ strategy is used, and the PEEP values are insufficient to prevent atelectasis.

The beneficial effects of sigh-augmented ventilation are also evident with patient-triggered modes of ventilation. Patroniti et $\mathrm{al}^{43}$ demonstrated an improvement in arterial oxygenation (PSV: $91.4 \pm 27.4 \mathrm{~mm} \mathrm{Hg}$ vs PSV + sigh: $133 \pm 42.5 \mathrm{~mm} \mathrm{Hg}, P<.001$ ), end-expiratory lung volume (PSV: 1,242 $\pm 507 \mathrm{~mL}$ vs PSV + sigh: 1,377 \pm 484 $\mathrm{mL}, P<.01$ ), and pulmonary compliance (PSV: $40.2 \pm$ $12.5 \mathrm{~mL} / \mathrm{cm} \mathrm{H}_{2} \mathrm{O}$ vs PSV + sigh: $45.1 \pm 15.3 \mathrm{~mL} / \mathrm{cm} \mathrm{H}_{2} \mathrm{O}$, $P<.01)$ when a sigh breath $(1 \mathrm{breath} / \mathrm{min})$ was applied to PSV in subjects with ARDS. There appear to be fewer and more variable benefits of an augmented breath in pulmonary and extrapulmonary ARDS. In 5 subjects with pulmonary ARDS and 5 subjects with extrapulmonary ARDS, Pelosi et $\mathrm{al}^{41}$ demonstrated significantly lower end-expiratory lung volumes after introduction of a sigh in subjects with pulmonary ARDS $(0.16 \pm 0.13 \mathrm{~L}$ vs $0.69 \pm 0.34 \mathrm{~L}$, respectively, $P<.01)$.

There is limited evidence on the frequency or the volume/pressure of the sigh breath that optimizes recruitment with ARDS. However, an inappropriately high frequency of sighs may be associated with ventilator-induced lung injury, similar to that seen with high $\mathrm{V}_{\mathrm{T}}(>12 \mathrm{~mL} / \mathrm{kg})$. In a murine model of paraquat-induced acute lung injury, Steimback et $\mathrm{al}^{44}$ demonstrated that a high frequency of sighs ( 180 breaths/h vs 10 breaths/h) was associated with increased lung and kidney cell apoptosis and type III procollagen mRNA expression.

\section{Variable Ventilation in Non-ARDS Models}

The beneficial effects of variable ventilation have been found to extend beyond the acute lung injury model. Mutch 
et al ${ }^{45}$ reported improved oxygenation, lower $\mathrm{P}_{\mathrm{aCO}}$, higher dynamic and static compliance, and lower total respiratory system resistance in a porcine methacholine-induced bronchospasm model. The improvement in pulmonary gas exchange and airway resistance is related to the positive effect of noise on both terminal airway opening and alveolar recruitment, both of which can be severely compromised with bronchospasm. One-lung ventilation is commonly performed in thoracic surgery to optimize the operative field. Side effects of one-lung ventilation include a large $\dot{\mathrm{Q}}_{\mathrm{S}} / \dot{\mathrm{Q}}_{\mathrm{T}}$ as a result of the controlled lung collapse and atelectasis of the dependent lung units and the gravitational effects of the lateral position on pulmonary blood flow. McMullen et $\mathrm{al}^{46}$ reported improved oxygenation and lower $\dot{\mathrm{Q}}_{\mathrm{S}} / \dot{\mathrm{Q}}_{\mathrm{T}}$ and $\mathrm{P}_{\mathrm{aCO}}$ when variable ventilation was applied to the dependent lung in a porcine one-lung ventilation study. The positive impact on pulmonary compliance was seen 60 min after the initiation of one-lung ventilation and was sustained after return to 2-lung ventilation.

\section{Practical Applications for Variable Ventilation}

There are no commercially available ventilators capable of performing variable ventilation. This does limit the use of this novel mode of ventilation by the respiratory therapist managing patients requiring controlled mechanical ventilation. However, the application of intermittent sigh breaths offers the opportunity to introduce some limited variability. The sigh breath is set to either 2 or 3 times the baseline $\mathrm{V}_{\mathrm{T}}$ or to a predefined plateau pressure. ${ }^{40}$ The sigh breath frequency should be limited to $2-3$ breaths/min to facilitate maximum recruitment without inducing volumerelated lung injury. ${ }^{4}$

In the absence of severe ARDS requiring muscle paralysis and controlled mechanical ventilation, rapidly transitioning to patient-triggered or spontaneous modes of ventilation has multiple benefits. ${ }^{47}$ Both patient-triggered ventilation and spontaneous ventilation facilitate better ventilation/perfusion matching, reduce ventilator-induced lung injury, and preserve diaphragmatic function. ${ }^{48-50}$

Furthermore, patient-triggered ventilation modes can potentially yield a highly variable respiratory pattern, akin to the experimental variable ventilation studies reported previously. Multiple modes of patient-triggered ventilation are currently available, and the respiratory therapist should utilize the most familiar mode. When a patient-triggered mode of ventilation is instituted, no additional ventilator settings are required to establish variability, as this will be patient-driven.

Proportional assist and neurally adjusted ventilatory assist are 2 modes of patient-triggered ventilation. In the former, the pressure support is proportional to the instantaneous flow and volume requirement. ${ }^{47}$ In contrast with the neurally adjusted ventilatory assist mode, the level of inspiratory support is related to the electrical inspiratory activity of the diaphragm. ${ }^{47}$ Both modes of ventilation yield a highly variable $\mathrm{V}_{\mathrm{T}}$ pattern and can initiate the beneficial effects of noise and stochastic resonance.

\section{Conclusions}

The current ventilatory strategy for the management of ARDS is to improve oxygenation and reduce intrapulmonary shunt by recruitment of previously collapsed alveoli. In addition, uninjured lung units must be protected from the deleterious effects of positive-pressure ventilation. Based on the best evidence to date, this involves ventilating with low $\mathrm{V}_{\mathrm{T}}(6 \mathrm{~mL} / \mathrm{kg}$ of predicted normal body weight $)$ and limiting plateau pressures to $<30 \mathrm{~cm} \mathrm{H}_{2} \mathrm{O}$ to prevent barotrauma while optimizing PEEP to reduce cyclical alveolar opening- and closing-related atelectrauma. There is less clear evidence regarding the optimum type of recruitment maneuver to perform when protective lung ventilation is employed.

Recruitment maneuvers include intermittent sustained inflation breaths, incremental increases in PEEP, prone positioning, and intermittent large $\mathrm{V}_{\mathrm{T}}$ breaths. The choice of the recruitment maneuver is influenced by the nature of the lung injury (primary vs secondary ARDS), extent of the lung injury, hemodynamic stability, and clinician experience. However, any recruitment maneuvers associated with high inspiratory pressures may result in deleterious cardiorespiratory changes. ${ }^{51}$

Variable ventilation offers a new physiological approach to lung recruitment without the negative hemodynamic effects from markedly elevated intrathoracic pressures. Although human data for variable ventilation are limited, animal data with variable ventilation in ARDS and nonARDS models are encouraging. Larger prospective human studies utilizing this novel strategy are needed to confirm the benefits shown by early animal data.

\section{REFERENCES}

1. Bendixen HH, Smith GM, Mead J. Pattern of ventilation in young adults. J Appl Physiol 1964;19:195-198.

2. Amato MB, Barbas CS, Medeiros DM, Magaldi RB, Schettino GP, Lorenzi-Filho G, et al. Effect of a protective-ventilation strategy on mortality in the acute respiratory distress syndrome. N Engl J Med 1998;338(6):347-354.

3. Slutsky AS, Ranieri VM. Ventilator-induced lung injury. N Engl J Med 2013;369(22):2126-2136.

4. Brewster JF, Graham MR, Mutch WA. Convexity, Jensen's inequality and benefits of noisy mechanical ventilation. J R Soc Interface 2005;2(4):393-396.

5. Suki B, Alencar AM, Sujeer MK, Lutchen KR, Collins JJ, Andrade JS Jr, et al. Life-support system benefits from noise. Nature 1998; 393(6681):127-128.

6. Lefevre GR, Kowalski SE, Girling LG, Thiessen DB, Mutch WA. Improved arterial oxygenation after oleic acid lung injury in the pig 


\section{Variability in Mechanical Ventilation}

using a computer-controlled mechanical ventilator. Am J Respir Crit Care Med 1996;154(5):1567-1572.

7. Mutch WA, Harms S, Lefevre GR, Graham MR, Girling LG, Kowalski SE. Biologically variable ventilation increases arterial oxygenation over that seen with positive end-expiratory pressure alone in a porcine model of acute respiratory distress syndrome. Crit Care Med 2000;28(7):2457-2464.

8. Lumb AB. Nunn's applied respiratory physiology, 7th edition. London: Elsevier; 2010:61-78.

9. Samoilov MS, Price G, Arkin AP. From fluctuations to phenotypes: the physiology of noise. Sci STKE 2006;2006(366):re17.

10. McDonnell MD, Abbott D. What is stochastic resonance? Definitions, misconceptions, debates, and its relevance to biology. PLoS Comput Biol 2009;5(5):e1000348.

11. Suki B, Barabási AL, Hantos Z, Peták F, Stanley HE. Avalanches and power-law behaviour in lung inflation. Nature 1994;368(6472): 615-618.

12. Perez-Padilla R, West P, Kryger MH. Sighs during sleep in adult humans. Sleep 1983;6(3):234-243.

13. Franco P, Verheulpen D, Valente F, Kelmanson I, de Broca A, Scaillet $\mathrm{S}$, et al. Autonomic responses to sighs in healthy infants and in victims of sudden infant death. Sleep Med 2003;4(6):569-577.

14. Bartlett D Jr. Origin and regulation of spontaneous deep breaths. Respir Physiol 1971;12(2):230-238.

15. Matsumoto S, Takeda M, Saiki C, Takahashi T, Ojima K. Effects of vagal and carotid chemoreceptor afferents on the frequency and pattern of spontaneous augmented breaths in rabbits. Lung 1997;175(3): 175-186.

16. Tryba AK, Peña F, Lieske SP, Viemari JC, Thoby-Brisson M, Ramirez JM. Differential modulation of neural network and pacemaker activity underlying eupnea and sigh-breathing activities. J Neurophysiol 2008;99(5):2114-2125

17. Vlemincx E, Van Diest I, Lehrer PM, Aubert AE, Van den Bergh O. Respiratory variability preceding and following sighs: a resetter hypothesis. Biol Psychol 2010;84(1):82-87.

18. Egbert LD, Bendixen HH. Effect of morphine on breathing pattern. A possible factor in atelectasis. JAMA 1964;188:485-488

19. Bell HJ, Azubike E, Haouzi P. The "other" respiratory effect of opioids: suppression of spontaneous augmented ("sigh") breaths. J Appl Physiol 2011;111(5):1296-1303.

20. Goodman NW, Kestin IG. Sighs and their effect on the breathing of patients anaesthetized with infusions of propofol. Br J Anaesth 1992; 68(1):48-53

21. Grim PS, Freund PR, Cheney FW Jr. Effect of spontaneous sighs on arterial oxygenation during isoflurane anesthesia in humans. Anesth Analg 1987;66(9):839-842.

22. Rocco PR, Zin WA. Pulmonary and extrapulmonary acute respiratory distress syndrome: are they different? Curr Opin Crit Care 2005; 11(1):10-17.

23. The Acute Respiratory Distress Syndrome Network. Ventilation with lower tidal volumes as compared with traditional tidal volumes for acute lung injury and the acute respiratory distress syndrome. $\mathrm{N}$ Engl J Med 2000;342(18):1301-1308.

24. Serpa Neto A, Cardoso SO, Manetta JA, Pereira VG, Espósito DC, Pasqualucci Mde O, et al. Association between use of lung-protective ventilation with lower tidal volumes and clinical outcomes among patients without acute respiratory distress syndrome: a meta-analysis. JAMA 2012;308(16):1651-1659.

25. Richard JC, Maggiore SM, Jonson B, Mancebo J, Lemaire F, Brochard L. Influence of tidal volume on alveolar recruitment. Respective role of PEEP and a recruitment maneuver. Am J Respir Crit Care Med 2001;163(7):1609-1613.

26. Levin MA, McCormick PJ, Lin HM, Hosseinian L, Fischer GW. Low intraoperative tidal volume ventilation with minimal PEEP is associated with increased mortality. Br J Anaesth 2014;113(1):97108

27. Arold SP, Suki B, Alencar AM, Lutchen KR, Ingenito EP. Variable ventilation induces endogenous surfactant release in normal guinea pigs. Am J Physiol Lung Cell Mol Physiol 2003;285(2): L370-L375.

28. Graham MR, Gulati H, Kha L, Girling LG, Goertzen A, Mutch WA. Resolution of pulmonary edema with variable mechanical ventilation in a porcine model of acute lung injury. Can J Anaesth 2011;58(8):740750.

29. Graham MR, Goertzen AL, Girling LG, Friedman T, Pauls RJ, Dickson $\mathrm{T}$, et al. Quantitative computed tomography in porcine lung injury with variable versus conventional ventilation: recruitment and surfactant replacement. Crit Care Med 2011;39(7):1721-1730.

30. Bellardine CL, Hoffman AM, Tsai L, Ingenito EP, Arold SP, Lutchen $\mathrm{KR}$, Suki B. Comparison of variable and conventional ventilation in a sheep saline lavage lung injury model. Crit Care Med 2006;34(2): 439-445.

31. Boker A, Haberman CJ, Girling L, Guzman RP, Louridas G, Tanner $\mathrm{JR}$, et al. Variable ventilation improves perioperative lung function in patients undergoing abdominal aortic aneurysmectomy. Anesthesiology 2004;100(3):608-616.

32. Kowalski S, McMullen MC, Girling LG, McCarthy BG. Biologically variable ventilation in patients with acute lung injury: a pilot study. Can J Anaesth 2013;60(5):502-503.

33. Gama de Abreu M, Spieth PM, Pelosi P, Carvalho AR, Walter C, Schreiber-Ferstl A, et al. Noisy pressure support ventilation: a pilot study on a new assisted ventilation mode in experimental lung injury. Crit Care Med 2008;36(3):818-827.

34. Spieth PM, Carvalho AR, Güldner A, Pelosi P, Kirichuk O, Koch T, Gama de Abreu M. Effects of different levels of pressure support variability in experimental lung injury. Anesthesiology 2009;110(2):342350 .

35. Haldane JS, Meakins JC, Priestley JG. The effects of shallow breathing. J Physiol 1919;52(6):433-453.

36. Laver MB, Morgan J, Bendixen HH, Radford EP Jr. Lung volume, compliance, and arterial oxygen tensions during controlled ventilation. J Appl Physiol 1964;19:725-733.

37. Ferris BG Jr, Pollard DS. Effect of deep and quiet breathing on pulmonary compliance in man. J Clin Invest 1960;39:143-149.

38. George P, Lapinsky SE. A sigh of relief for ARDS? Respir Care 2009;54(7):839-840

39. Badet M, Bayle F, Richard JC, Guérin C. Comparison of optimal positive end-expiratory pressure and recruitment maneuvers during lungprotective mechanical ventilation in patients with acute lung injury/ acute respiratory distress syndrome. Respir Care 2009;54(7):847-854 .

40. Pelosi P, Bottino N, Chiumello D, Caironi P, Panigada M, Gamberoni $\mathrm{C}$, et al. Sigh in supine and prone position during acute respiratory distress syndrome. Am J Respir Crit Care Med 2003; 167(4):521-527.

41. Pelosi P, Cadringher P, Bottino N, Panigada M, Carrieri F, Riva E, et al. Sigh in acute respiratory distress syndrome. Am J Respir Crit Care Med 1999;159(3):872-880.

42. Rival G, Patry C, Floret N, Navellou JC, Belle E, Capellier G. Prone position and recruitment manoeuvre: the combined effect improves oxygenation. Crit Care 2011;15(3):R125.

43. Patroniti N, Foti G, Cortinovis B, Maggioni E, Bigatello LM, Cereda M, Pesenti A. Sigh improves gas exchange and lung volume in patients with acute respiratory distress syndrome undergoing pressure support ventilation. Anesthesiology 2002;96(4):788-794.

44. Steimback PW, Oliveira GP, Rzezinski AF, Silva PL, Garcia CS, Rangel G, et al. Effects of frequency and inspiratory plateau pressure during recruitment manoeuvres on lung and distal organs in acute lung injury. Intensive Care Med 2009;35(6):1120-1128. 


\section{Variability in Mechanical Ventilation}

45. Mutch WA, Buchman TG, Girling LG, Walker EK, McManus BM, Graham MR. Biologically variable ventilation improves gas exchange and respiratory mechanics in a model of severe bronchospasm. Crit Care Med 2007;35(7):1749-1755.

46. McMullen MC, Girling LG, Graham MR, Mutch WA. Biologically variable ventilation improves oxygenation and respiratory mechanics during one-lung ventilation. Anesthesiology 2006;105(1):91-97.

47. Güldner A, Pelosi P, Gama de Abreu M. Spontaneous breathing in mild and moderate versus severe acute respiratory distress syndrome. Curr Opin Crit Care 2014;20(1):69-76.

48. Carvalho NC, Güldner A, Beda A, Rentzsch I, Uhlig C, Dittrich S, et al. Higher levels of spontaneous breathing reduce lung injury in experimental moderate acute respiratory distress syndrome. Crit Care Med 2014;42(11):e702-e715.

49. Güldner A, Braune A, Carvalho N, Beda A, Zeidler S, Wiedemann $\mathrm{B}$, et al. Higher levels of spontaneous breathing induce lung recruitment and reduce global stress/strain in experimental lung injury. Anesthesiology 2014;120(3):673-682.

50. Kallet RH. Patient-ventilator interaction during acute lung injury, and the role of spontaneous breathing: part 1: respiratory muscle function during critical illness. Respir Care 2011;56(2):181-189.

51. Odenstedt H, Aneman A, Kárason S, Stenqvist O, Lundin S. Acute hemodynamic changes during lung recruitment in lavage and endotoxin-induced ALI. Intensive Care Med 2005;31(1):112-120. 